\title{
EXAMINING VIRTUAL REFERENCE SERVICES IN ACADEMIC LIBRARIES IN THE MIDDLE EAST
}

\author{
Zahraa A. Abul ${ }^{1}$ \\ Aysha M. Alkandari ${ }^{1}$ \\ ${ }^{1}$ Library information systems department, graduate studies at Kuwait university, Kuwait
}

\begin{abstract}
This research focuses on examining the availability of Virtual Reference Services in academic libraries in the Middle East. Virtual Reference Services could be provided in several ways, for example: by telephone, email, live chat, video conferencing, texting, and recently using social media applications like Twitter. This research will explore the presence of Virtual Reference Services in Middle Eastern academic libraries, and the ways in which they are presented. 55 academic libraries' websites have been examined with a checklist that includes: the nature of reference services available, the time it took to locate the Virtual Reference Services, the text included in the link to describe the services, and the number of links navigated on the webpage to find the reference services. The main objective of this research is to examine the use of Virtual Reference Services in Middle Eastern university libraries and to increase the awareness of the libraries' resources and services. Findings of this study showed that live chat as a Virtual Reference Service in the Middle East is not very prevalent. In addition, it was found that email as a means of virtual communication is used most commonly by the academic libraries that provided Virtual Reference Services.
\end{abstract}

Key Words: Virtual Reference Service; reference services; chat; instant messaging; academic libraries; web forms.

\section{Introduction}

Libraries have long since been present within communities and active in order to serve local people. Reference services constitute one of the key resources provided by academic libraries over time. Reference services traditionally are known to be provided at a desk, but with all the technological changes of recent years and decades, libraries have adapted and begun to change. Virtual Reference Services could be provided in several ways - for example, by telephone, email, live chat, video conferencing, texting and recently using social media applications like Twitter. It could be synchronous, for example with live chat, or asynchronous, like email, or a web form.

There are different strategies mentioned in ALA professional guidelines that lead to successful provision of reference and user services such as: access, responsiveness, design of services, critical thinking, knowledge base, environmental scanning, application of knowledge, active learning, marketing awareness, assessment, communication and outreach, evaluation, collaboration, and more. In this research we intend to focus on utilizing those strategies to enhance the importance of using Virtual Reference Services in the Middle East, and to support our findings. 
Many users conduct most of their research from home, or elsewhere outside the library. With this trend, as the content libraries offer becomes more web-based and more actively used by patrons physically outside the libraries, there is a need to provide effective Virtual Reference Services. "This means that libraries - as service-oriented organizations - need to offer access to reference services in a way that's as obvious and as convenient for the remote user as is access to the information itself' (Bakker, 2002).

Virtual reference librarians assist all library users in many ways. They provide users with instructions, advice, or direct assistance in order to help the users in accessing all forms of knowledge. Reference librarians can contact users either directly or indirectly. It is highly important for a librarian to provide the service in a specific behavioral way that concentrates on a high level of approachability, interest, listening/inquiring, searching and follow-up. These competencies qualify a librarian to provide an effective assessment that will eventually help users to meet their information needs. The primary focus of a reference librarian is to understand information needs and information behavior of primary users, and then to develop the skills to effectively meet those information needs.

Lastly, Virtual Reference is a great service offered by libraries everywhere. While it is clear that search engines are full of information, the librarian has the skills to search and evaluate, in order to bring the users the most timely, relevant and accurate information. Having this service within users' reach makes it almost as easy as searching in a search engine, especially when using the texting or social media applications, and often with higher-quality results. Libraries will always adapt to changes, and as new technologies are being developed, future reference services might look completely different from what we have now.

This research aim is to identify and examine Virtual Reference Services in Middle Eastern university libraries. In addition, we aim to explore the level of awareness of Virtual Reference Services offered by academic libraries in the Middle East. The main research questions for us as researchers are:

- What types of Virtual Reference Service are commonly used in academic libraries in the middle east?

- How are Virtual Reference Services presented in academic libraries in the Middle East?

This study is significant because it will help in seeing where Middle Eastern academic libraries stand when it comes to Virtual Reference Services, and how much they need to improve and change. The results of this study will add to the literature, as there is a lack of studies concerning Virtual Reference Services in the Middle East.

\section{Scientific Background}

The existing literature covers different aspects of Virtual Reference Services. Some studies focus on the usability of Virtual Reference Services on academic library websites; for example, Yang, and Dalal (2015) studied a random sample of academic libraries' websites for reference-related activities. Their study investigated if the library provided a reference service on the main page, the terminology used to describe the reference service, the availability of a chat service, and the availability of other types of Virtual Reference Services, such as email, phone, video chat, text messaging. Universities that offer advanced degrees are more likely to offer chat than the ones that 
offer lower-level degrees. A similar study (Brown \& Swan, 2007) also demonstrated the importance of Virtual Reference Service in academic libraries in relation to supporting scholars research process. Another study by Dee and Allen (2006) examined the usability of digital reference services on academic health science library websites; they found that $18 \%$ of the libraries they surveyed offered chat. When checking the location of the link to the service, $14.3 \%$ of the libraries did not offer a link to the service on their homepage, while $78.6 \%$ did provide this on their homepage. Moreover, a study by Conway et al. (2008) summarized the use of Virtual Reference Services according to users' demands and to fulfill librarians' needs for help and assistance.

Mu et al. (2011) focused on the accessibility of Virtual Reference Services in academic libraries. Their paper investigated the way Virtual Reference Services are presented in academic libraries, and then focused on how to make Virtual Reference Services more accessible for patrons. In addition, they proposed a model to expand the use of Virtual Reference Services. Their study found that $80 \%$ of the academic libraries they surveyed had homepage access to Virtual Reference Service, while $18 \%$ did not; they found that $85 \%$ of the academic libraries the studied offered realtime communication with the reference librarian, while $13 \%$ offered email only as a Virtual Reference Service. Similar to this study, Arellano (2001) demonstrated the main characteristics of the Virtual Reference Service via electronic mail. This study mentioned the way libraries' reference departments establish that service as a link on the library home page, allowing a great increase in the number of consultations.

On the other hand, Bakker's (2002) study indicated that, despite their limitations, the best of the commercial Web-based customer service applications - such as eGain, Cisco's Customer Contact Solutions, LivePerson, WebHelp and Humanclick - offer a whole suite of interactive technologies that have proved to be useful for live online reference. Bakker's study aimed to show the benefits of adopting certain technologies and service models to virtual reference applications. Another similar study by Kolthuri (2014) confirms the same perception about technological development with regard to Virtual Reference Services. From another perspective, Hendricks and Buchanan (2012) studied librarians' job satisfaction with virtual reference. Their objective was to create a survey to find ways to improve both the service and the experience of chat librarians. They found that $77 \%$ of the librarians said that they enjoyed answering the chat questions, while $23 \%$ said that they did not enjoy it. Furthermore, $76 \%$ of the librarians indicated that they received written abuse; $28 \%$ of the abuse was swearing. $24 \%$ of them stated that they felt like their time had been wasted, while $18 \%$ felt angry.

From another perspective, a study by Pinto and Manso (2012), aimed to research the shift of technology used in virtual services provided to users by academic communities. The purpose was to design the study in a way that compared both quantitative and qualitative methods. It demonstrated that Virtual Reference Services in the university had not changed significantly since they first appeared. Similar to the previous study, but with a closer look at technologies for virtual references such as Skype and Twitter, it showed that the vast majority of libraries (of all types) using Twitter continue to use it as a communications and public relations mechanism - tweeting about resources, services, events and/or community information. Moreover, those libraries had reported experimenting with Skype as far back as 2008 when Char Booth, then at Ohio University, described that library's experience offering Skype as a means of interacting with reference staff (Beaton, 2012). 
Other studies focused on comparing in-person with Virtual Reference Services. For example, Nilsen (2006) compared users' perspectives regarding in-person and Virtual Reference Services. The study found lower satisfaction for virtual reference than in-person reference.

Previous research has also studied the level of adherence to professional guidelines when it comes to Virtual Reference Services. For example, Shachaf and Horowitz (2008) evaluated and compared the level of adherence to professional guidelines that were published by International Federation of Library Association (IFLA), American Library Association (ALA), and Reference and User Service Association (RUSA). They found a low level of adherence and no relation between adherence to the guidelines and user satisfaction.

There are not many studies conducted regarding the examination of academic libraries in the Middle East. However, one study by Rahaman and Ansari (2011) investigated the availability of Virtual Reference Services in King Fahad University of Petroleum and Minerals in Kingdom of Saudi Arabia. Their study revealed that the library started their Ask a Librarian service in 2011, where users submit their queries using a web form or email. The library has no real-time chat service. As such, this study will help to bridge the gap in the literature regarding Virtual Reference Service availability in this region

To conclude, libraries play a crucial role in the information exchange regarding technology revolution. New communication tools have emerged in providing Virtual Reference Services; these include IM and embedded chat. "IM is definitely the way forward for online reference service. The positive aspects of IM are that it is relatively easy, cheap to set up, flexible, and so can respond to changes in technology and the user's habits" (Lihitkar, 2011). Studies by Boss (2014) and Flanagin (2005) confirmed the use of IM as a way to elicit all the needed information for users, and stated that it is the most effective way for communication between users and reference librarians. Also, Lancaster (2007), Nachbaur (2003) and Ruppel \& Fagan (2002) made it clear to readers that advantages of IM are many and diverse; it is the most frequently used communication method in Virtual Reference Services.

\section{Methodology}

This research investigates the availability of Virtual Reference Services in Middle Eastern Academic libraries. The top 100 Arab World Universities are ranked on the "Webometrics" website according to five ranking criteria (namely excellence, openness, impact, presence, and world rank). Choosing these 100 Middle Eastern universities as a sample, each university website was visited to locate their library website. Subsequently, each of these library websites was examined to determine whether they provide Virtual Reference Services. The two researchers divided the 100 university websites between them, each researcher checking 50 websites. Each website was examined thoroughly to find the Virtual Reference Service, and if the Virtual Reference Service was not visible on the home page, the search engine within the website was used to locate it; if the website did not include its own search engine, the sitemap was used to locate the Virtual Reference Service. Out of the top 100 universities, it was found that 55 academic libraries provided Virtual Reference Service in their library websites. These 55 differed in purpose and usability. 
A checklist was developed to evaluate the 55 academic libraries' websites, across three different areas related to Virtual Reference Services: the accessibility of the service on the website, the organization of content on the website, and the support provided by the website for the users to assist in providing Virtual Reference Services. The checklist went into more detail in each category, covering points such as: the nature of reference services available; the time it took to locate the Virtual Reference Services; the text included in the link to describe the service; and the number of links navigated on the webpage to find the reference service. This paper's checklist consists of 14 questions that combine yes/no responses with open-ended questions. The subset of ready reference questions was further analyzed in order to define the accessibility and availability of Virtual Reference Service from Dee and Allen (2006). The checklist results were quite interesting, showing that 14 of 55 (20.9\%) academic libraries used live chat as a way of communication. This low percentage grabs our attention, and highlights the need for improving Virtual Reference Services in the Middle East when compared to other universities globally.

It was found, by relating to a study by Radford (2008), that users' expectations of Virtual Reference Services are related to how information is actually delivered. Therefore, the present researchers' attention turns to new directions of investigation that will help in developing the Virtual Reference Services in Middle Eastern academic libraries. For both librarians and users, this study opens up channels for discovering characteristics of Virtual Reference Services, exploring new tools used in the reference service, and recognizing the level of awareness of Virtual Reference Services in the Middle East. For that reason, we have succeeded in analyzing the most used type of Virtual Reference Service amongst those 55 academic libraries. For Middle Eastern academic libraries, email was the most comfortable way to contact with reference librarians. Using content data analysis, we suggest ways to provide data on the use of Virtual Reference Services, and better solutions for developing this service as a core part of Middle Eastern libraries' websites.

\section{Results}

Virtual Reference Services in Middle Eastern university libraries is being evaluated according to three main categories. Mapping the virtual reference features into categories helps us in achieving the aim of this study. In this paper, the categories to be discussed are accessibility of the Virtual Reference Service on the website, organization of content on the website, and support provided to assist users with the service. Starting with the first category, accessibility covers ease of access and approachability for users when accessing virtual services. This category analyzes four different areas tested as patterns that contribute to the accessibility of Virtual Reference Services. These are: types of virtual services listed in the website, time of browsing the library website before locating Virtual Reference Services, number of links navigated to get to the Virtual Reference Service page, and the number of links to get to the chat service. Table 1 shows the results of the analyzed areas. It was found that, with regard to types of Virtual Reference Service listed in the library website, $79.1 \%$ of academic libraries in the Middle East offered email as a Virtual Reference Service. This email service includes an enquiry form that can be submitted and answered via email within a specific number of days, or the library providing an email address that the user can contact. Meanwhile, $20.9 \%$ of academic libraries in the Middle East offered live chat as a reference service. The description of the service varied between ask us, ask a librarian, and reference service. 
Another area that is related to accessibility here is the time taken to find and access the services. It is found that $30 \%$ of the studied websites were browsed in 1 minute or less to locate the email Virtual Reference Service, while $40 \%$ of them took 2 minutes to locate the email Virtual Reference Service. $12.5 \%$ were browsed in 3 to 4 minutes, and a further $12.5 \%$ were browsed in 5 to 6 minutes to locate the email Virtual Reference Service. At the very top end, 5\% of websites took 7-10 minutes before being able to locate information indicating whether the library offered Virtual Reference Service in the form of email.

$46.6 \%$ of the 14 academic libraries that offered live chat as a reference service were browsed within 1 minute to locate the live chat; $40 \%$ took 2 minutes; and $6.6 \%$ was the case for both the $3-4$ minute, and 7-10 minute ranges.

Lastly, the third area is number of links to get from the home page to the digital reference services page. Results show that $52 \%$ of the studied Middle Eastern library websites used one link to reach the Virtual Reference Service page. 30\% used two links, and 17.5\% required the use of 3-4 links to reach the Virtual Reference Service page in the library's website.

Finally, results the number of links takes the user to get to the chat service page are $53.5 \%$ using only 1 link, 26.6\% needing 2 links, and 20\% needing 3-4 links to reach the live chat service.

Table 1. The accessibility of Virtual Reference Service on the website.

\begin{tabular}{|c|c|c|c|c|c|c|}
\hline \multicolumn{7}{|l|}{ Accessibility } \\
\hline $\begin{array}{c}\text { VIRTUAL REFERENCE } \\
\text { SERVICE Type }\end{array}$ & \multicolumn{3}{|c|}{ Email (41) $79.1 \%$} & \multicolumn{3}{|c|}{$\begin{array}{c}\text { Live chat } \\
\mathbf{2 0 . 9 \%}\end{array}$} \\
\hline \multirow{6}{*}{$\begin{array}{l}\text { Minutes to locate VIRTUAL } \\
\text { REFERENCE SERVICE on the } \\
\text { website }\end{array}$} & Minutes & & $\overline{\mathbf{P}}$ & Minutes & $\mathbf{F}$ & $\overline{\mathbf{P}}$ \\
\hline & $1 \mathrm{~min}$ & 12 & $30 \%$ & $1 \mathrm{~min}$ & 7 & $46.6 \%$ \\
\hline & $2 \mathrm{~min}$ & 16 & $40 \%$ & $2 \mathrm{~min}$ & 6 & $40 \%$ \\
\hline & $3-4$ min & 5 & $12.5 \%$ & $3-4 \min$ & 1 & $6.6 \%$ \\
\hline & $5-6 \mathrm{~min}$ & 5 & $12.5 \%$ & $5-6 \min$ & 0 & $0.00 \%$ \\
\hline & $7-10 \mathrm{~min}$ & & $5 \%$ & $\begin{array}{l}7-10 \\
\min \end{array}$ & 1 & $6.6 \%$ \\
\hline \multirow{4}{*}{$\begin{array}{l}\text { Number of links to reach VIRTUAL } \\
\text { REFERENCE SERVICE page }\end{array}$} & Links & $\mathbf{F}$ & $\mathbf{P}$ & Links & $\mathbf{F}$ & $\mathbf{P}$ \\
\hline & 1 link & 21 & $52 . \%$ & 1 link & 8 & $53.3 \%$ \\
\hline & 2 links & 12 & $30 \%$ & 2 links & 4 & $26.6 \%$ \\
\hline & 3-4 links & & $17.5 \%$ & $\begin{array}{c}3-4 \\
\text { links }\end{array}$ & 3 & $20 \%$ \\
\hline
\end{tabular}

To conclude, as demonstrated above in table 1, an email enquiry form is the most used Virtual Reference Service used in today's real-time communication in Middle Eastern libraries. On the other hand, a study by Lihitkar (2011) concluded that IM (instant messaging) and embedded chat provide the most effective communication tools between librarians and users. This is because it is relatively easy to use and cheap to implement; it also boasts high responsiveness. Similar to these 
findings Sean et al. (2007) demonstrated that the effectiveness of IM offers many advantages over email for college students and academic users. It is highly recommended for Middle Eastern libraries shift their Virtual Reference Service from email to IM or embedded chat; this will be an improvement for their virtual services and for the libraries as a whole.

As discussed before, three main categories are demonstrated in this paper regarding Virtual Reference Service in Middle Eastern university libraries. The second is organization of content. This element describes the relationship of content in the website, and how well it is organized in a way that make it easy for users to access and reach the Virtual Reference Service. Organization of content in this paper is about five areas: confusing description of the Virtual Reference Service presented in divided sections on the page, well organized content of the library website, use of graphical buttons as a link for the Virtual Reference Service, and clear labelling of the graphical buttons (when used).

The results for this section can be seen in table 2. With the first question, $81.8 \%$ of Middle Eastern libraries have no problem in the words presented in the website; the other $18.2 \%$ are guilty of having non-understandable words (such as bibliotheque, accueil, anglais).

Results for using divided window (or frame) to present content of the website that contributes to locating information on the digital reference service easily, are as follows: $18.2 \%$ of libraries' websites in Middle Eastern universities do not use divided window, while $81.8 \%$ use divided window as a feature that organizes library's website content. The third area in organizational content category is the organization of the site in a way that makes it easy to find the link leading to digital reference service. $78.2 \%$ of the websites examined were organized, while $21.8 \%$ were relatively disorganized.

Moving toward the use of graphical button as links to the digital reference service area; results show that $70.9 \%$ of the libraries' websites are not using graphical buttons, while $29.1 \%$ of them do. Finally, defining whether the website of a library is well organized could be through the presentation of graphical buttons. As for how clearly these buttons were identified and labeled, $77.8 \%$ were clearly labeled, and $22.22 \%$ was the percentage of library's website that used unclear graphical buttons as a link to the Virtual Reference Service.

Table 2. The organization of content on the website.

\begin{tabular}{|c|c|c|c|c|}
\hline & \multicolumn{2}{|r|}{ Yes } & \multicolumn{2}{|r|}{ No } \\
\hline \multirow{2}{*}{$\begin{array}{l}\text { Confusing discerption of the VIRTUAL REFERENCE } \\
\text { SERVICE }\end{array}$} & $\mathbf{F}$ & $\mathbf{P}$ & $\mathbf{F}$ & $\mathbf{P}$ \\
\hline & 10 & $18.18 \%$ & 45 & $81.82 \%$ \\
\hline $\begin{array}{l}\text { VIRTUAL REFERENCE SERVICE presented in a divided } \\
\text { section on the page }\end{array}$ & 45 & $81.82 \%$ & 10 & $18.18 \%$ \\
\hline Website is well organized & 43 & $78.18 \%$ & 12 & $21.82 \%$ \\
\hline $\begin{array}{l}\text { VIRTUAL REFERENCE SERVICE link is presented as a } \\
\text { graphical button }\end{array}$ & 16 & $29.09 \%$ & 39 & $70.91 \%$ \\
\hline Graphical buttons when used were clear & & $22.22 \%$ & 4 & $77.78 \%$ \\
\hline
\end{tabular}


In conclusion, it is obvious from our findings that a clear and well-organized content of the website enriches the efficiency of the Virtual Reference Service. Organized content really matters, because it defines the overall purpose of the services and provides instructions for users. Also, a wellorganized library website answers all the user's information needs, directs them to additional information sources, and provides background information. Similar to our findings, Bakker's (2002) study demonstrates the importance of well-organized content.

As for the final category in this study, support plays a crucial role in Virtual Reference Services. Libraries select and present the most important materials that support their mission and are relevant to the community's needs. Their role is to bring together the most relevant information and resources which meet users' needs. Librarians must know these needs and reflect those in the service and resources provided. This process could happen through providing search engines to find Virtual Reference Services, alerts or links inviting emails to ask questions related to their investigations, help screens and FAQs, and useful and effective site maps or site index to locate Virtual Reference Service chat functions.

It appears that $70.9 \%$ of the studied Middle Eastern University libraries' websites provide search engines to help find the digital reference services, while $29 \%$ do not. Also, there must be a link inviting email to contact and ask questions about the site; results show that $58.1 \%$ of Middle Eastern libraries use this feature in their website, while $41.8 \%$ don't. Moreover, a help screen and FAQs could be defined as type of support for libraries' website users, because they assist with the location of the Virtual Reference Service, whatever form it takes. In this study, $43.6 \%$ of help/FAQ areas helped in locating the Virtual Reference Service, while 56.3\% did not help in locating the Virtual Reference Service on the Middle Eastern libraries' websites.

A website map was used in only $7.2 \%$ of the examined academic library websites. It could be argued that it was used only four times because other libraries' websites provided the Virtual Reference Service in a very clear and reachable way, so that the sitemap was not needed. Finally, it was found that when the sitemap was used to locate a chat service, only $50 \%$ of Middle Eastern libraries' sitemaps were helpful. Because the site map was used only in the case of four universities, results show that using site map was helpful two times, and wasn't helpful two times, when it comes to locating Virtual Reference Services in those universities.

Table 3. The support provided to assist users.

\begin{tabular}{|l|cc|cc|}
\multicolumn{1}{|c|}{ Support } & \multicolumn{2}{c|}{ Yes } & \multicolumn{2}{c|}{ No } \\
\hline Availability of 'Contact us' & F & P & F & P \\
\cline { 2 - 5 } & 32 & $58.18 \%$ & 23 & $41.82 \%$ \\
\hline Availability of search engine & 39 & $70.91 \%$ & 16 & 29.09 \\
\hline Use of website map to locate chat service & 4 & $7.27 \%$ & 51 & $92.73 \%$ \\
\hline $\begin{array}{l}\text { Help/FAQ helped in locating the VIRTUAL REFERENCE } \\
\text { SERVICE }\end{array}$ & 24 & $43.6 \%$ & 31 & $56.3 \%$ \\
\hline
\end{tabular}


Support in Virtual Reference Services is designed to be consulted rather than read through. It is a specific type of aid provided to users to help them get the required information. This type of support, when provided by Middle Eastern libraries' websites, proved to be effective especially in using site maps and search engines. On the other hand, $45.45 \%$ of the library websites' help and FAQ sections did not help in locating Virtual Reference Services. A study by Yang and Dalal (2014) found that $11.6 \%$ of their sample had an FAQ section on their website. Support through help screens or FAQs answers user questions and helps them in reaching their navigation goals. Also, it guides and aids users in selecting the most suitable resource. Finally, support is a very important category in evaluating Virtual Reference Service in libraries because it promotes the library within the user community.

\section{Discussion}

When gathering the sample, we found that, out of the top 100 Arab World universities according to webometrics.info, 55 university libraries offered Virtual Reference Service in various ways, including email, live chat and phone. It was expected to find a small sample - perhaps smaller than 55. This indicates that Middle Eastern academic libraries are not totally behind when it comes to providing Virtual Reference Services. In addition, it was expected that the majority of Middle Eastern academic libraries would offer email as the only way of communication for their Virtual Reference Service; this speculation was confirmed as $70.9 \%$ of the sample offered email as the only method to communicate with patrons regarding the reference service.

While Virtual Reference Service is expected to determine the situational context of the individual information needs of academic libraries users. At the same time, findings in Middle Eastern libraries show that organizational content helps in providing and determining users' information needs. In addition, it is obvious from Table 2 that clear and well-organized content of the website enriches the efficiency of the Virtual Reference Service.

It was found that 14 out of 55 (20.9\%) academic libraries used live chat as a way of communication. This low number shows that Middle Eastern libraries need to improve their Virtual Reference Service when compared to other universities; for example, Mu et al.'s (2011) study found that the majority $(85 \%)$ of their sample offered real-time communication with a reference librarian. Academic libraries in the Middle East need to shift to new, more advanced technologies in offering reference services and not only depend on email as a reference service. Furthermore, some academic libraries are now using social media applications to provide reference services, for example Twitter is offered as a reference service by Johns Hopkins University Libraries (Beaton, 2012). This finding helps us in summarizing and analyzing what information sources should be and are recommended to users. Those sources must be available in specific features such as attractiveness, interests, and content level for each user.

The results indicated that $58.1 \%$ of the academic libraries' Virtual Reference Services can be reached within 1 link. This result indicates that more than half of our sample offered easy access to their Virtual Reference Service. Having the service within the reach of the user can ensure more use and awareness of the service. Our results also indicated that the majority $(81.1 \%)$ of academic libraries in the Middle East that offer Virtual Reference Services did not use confusing words or jargon to describe the service. These results are similar to Dee and Allen's (2006) findings, where 
$92.9 \%$ of academic health science library websites did not use a confusing word to describe the service.

Further presentation of the most popular communication tool for Virtual Reference Service, which is IM (instant messaging) was found to be used by other libraries. IM is considered as a real-time communication tool with little expense and technical expertise required (Lihitkar, 2011). It is frequently used amongst library users to mediate communication when they choose to ask for help (Radford and Conway, 2007). Moreover, there are different characteristics distinguishing the uniqueness of this tool over other tools that elicit information from users, such as getting feedback about a specific article. One example is Southern Illinois University's Morris Library; they developed a survey for comparing IM and a traditional reference disc. The survey results showed that IM service had so many advantages and students prefer consulting librarians though IM instead of visiting the reference disc (Ruppel and Fagan, 2002).

While our findings for Middle Eastern libraries show that the most used communication tool is "email", only 14 academic libraries out of 55 used live chat as their Virtual Reference Service. This low percentage for Middle Eastern top academic libraries indicates that they are not keeping pace with technological developments, and little attention is being directed to developing their services and resources. On the other hand, the 14 libraries which were focused on providing highquality services though combining resources and information technologies. Also, their missions are oriented to reinforce the library's role in the learning process. All 14 libraries provide welldesigned collections, well-organized content, and a variety of academic resources. In addition, they are offering experts and well-trained staff to assist, direct, and give instructions to users. So, the IM reference service should be considered useful in satisfying users' needs compared to both Email and traditional reference services.

The univesities that are providing live chat are: American University of Beirut, Qatar University, American University in Cairo, Umm Al Qura university, Texas A\&M University at Qatar, Lebanese American University, Khalifa University of Science, Technology, and Research, Taibah University, Zayed University, University of Baghdad, British University in Egypt, University Ferhat Abbassetif, Imam Abdulrahman Bin Faisal, and Abu Dhabi University. 
Table 4. Universities that provide live chat as a reference service.

\begin{tabular}{|c|c|c|c|}
\hline Universities & $\begin{array}{l}\text { Minutes to locate } \\
\text { VIRTUAL } \\
\text { REFERENCE } \\
\text { SERVICE on the } \\
\text { website } \\
\end{array}$ & $\begin{array}{l}\text { Number of } \\
\text { links to } \\
\text { reach live } \\
\text { chat }\end{array}$ & Other features \\
\hline $\begin{array}{l}\text { American University } \\
\text { of Beirut }\end{array}$ & $1 \mathrm{~min}$ & 1 & $\begin{array}{c}\text { Ask a librarian- meet } \\
\text { with a librarian }\end{array}$ \\
\hline Qatar University & $1 \mathrm{~min}$ & 2 & $\begin{array}{l}\text { Ask us, e-payment } \\
\text { services }\end{array}$ \\
\hline $\begin{array}{l}\text { Lebanese American } \\
\text { University }\end{array}$ & $1 \mathrm{~min}$ & 1 & $\begin{array}{l}\text { Information for new } \\
\text { students about the } \\
\text { VIRTUAL } \\
\text { REFERENCE SERVICE }\end{array}$ \\
\hline $\begin{array}{l}\text { Khalifa University of } \\
\text { Science, Technology, } \\
\text { and Research }\end{array}$ & $3 \min$ & 1 & $\begin{array}{l}\text { LibGuides, academic } \\
\text { tools }\end{array}$ \\
\hline Taibah University & $1 \mathrm{~min}$ & 1 & - \\
\hline Zayed University & $1 \mathrm{~min}$ & 1 & $\begin{array}{l}\text { Search knowledge base, } \\
\text { submit a question }\end{array}$ \\
\hline $\begin{array}{l}\text { University of } \\
\text { Baghdad }\end{array}$ & $2 \min$ & 1 & - \\
\hline $\begin{array}{l}\text { British University in } \\
\text { Egypt }\end{array}$ & $2 \min$ & 1 & $\begin{array}{l}\text { Srs-booking, subject } \\
\text { maps }\end{array}$ \\
\hline $\begin{array}{l}\text { University Ferhat } \\
\text { Abbassetif }\end{array}$ & $7 \mathrm{~min}$ & 3 & - \\
\hline $\begin{array}{l}\text { Imam Abdulrahman } \\
\text { Bin Faisal }\end{array}$ & $2 \min$ & 2 & Ask a librarian \\
\hline $\begin{array}{l}\text { Abu Dhabi } \\
\text { University }\end{array}$ & $2 \min$ & 1 & App store, Google \\
\hline $\begin{array}{l}\text { American University } \\
\text { in Cairo }\end{array}$ & 1 & 1 & $\begin{array}{c}\text { How do I?, e-research } \\
\text { problems }\end{array}$ \\
\hline $\begin{array}{l}\text { Umm Al Qura } \\
\text { University }\end{array}$ & 2 & 3 & Mobile apps \\
\hline $\begin{array}{l}\text { Texas A\&M } \\
\text { University at Qatar }\end{array}$ & 2 & 2 & - \\
\hline
\end{tabular}




\section{Conclusion}

In conclusion, the results of our study show that Middle Eastern academic libraries need to enhance their services to match with other academic libraries in the world when in providing Virtual Reference Services, including chat service, social media, and texting as ways of communication with the virtual librarian, results in frequent usage for the service. In addition, these forms of communication facilitate easy access to the library services. Some of the limitations that we faced when conducting the study were the lack of clear and labeled links to the library website in the home page of the universities' websites. Also, some of the websites were in French as the only language. Lastly, some links were slow and unresponsive within the website.

There is a need for Middle Eastern academic libraries to use IM as a communication tool rather than email. Using email only means that it can be difficult to conduct an effective reference interview, while using IM provide 24/7 communication with librarians. This is because many questions require detailed clarifications which will take time, effort, and would not encourage users to use Virtual Reference Service.

Future research should focus on examining a larger sample to include more academic libraries. Furthermore, we suggest for future studies to focus their investigations on the effectivity of Virtual Reference Service in Middle Eastern academic libraries. It is also important to test the perception of the users when it comes to Virtual Reference Services in the Middle East. Moreover, we suggest specific works that relate to user comments and to ensuring a high user satisfaction.

Our research has added value to reference service literature as it is the only study done in top Middle East academic libraries. Middle Eastern libraries need to engage users in discussions about experience related to their information needs. Finally, as discussed above, regarding users pursuing their own preference in research, it is recommended to provide IM tools in all Middle Eastern libraries' websites; this can help guide users to determine the direction of their investigations. 


\section{References}

Abubaker, M. (2021). "Implementation and Use of Virtual Reference Services in Academic Libraries during and post COVID-19 Pandemic: A Necessity for Developing Countries" (2021). Library Philosophy and Practice (e-journal). 4951.

Arellano, M. (2001). Virtual Reference Services. Information Science, 30(2), 7-15.

Bakker, T. (2002). Virtual Reference Services: Connecting Users with Experts and Supporting the Development of Skills. Liber Querterly, 12(2-3), 124-137.

Beaton, B. (2012). New Technologies for Virtual Reference: a look at Skype and Twitter.

Boss, R. W. (2010). Virtual Reference. American Library Association.

Brown, S., \& Swan, A. (2007). Researchers' use of academic libraries and their services: a report commissioned by the Research Information Network and the Consortium of Research Libraries.

Connaway, L. S., Radford, M. L., \& Dickey, T. J. (2008). Virtual Reference Services: On the trail of the elusive non-user: What research in virtual reference environments reveals. Bulletin of the Association for Information Science and Technology, 34(2), 25-28.

Dee, C., \& Allen, M. (2006). A Survey of the Usability of Digital Reference Services on Academic Health Science Library Web Sites. The Journal of Academic Librarianship, 32(1), 69-78.

Flanagin, A. J. (2005). IM online: Instant messaging use among college students. Communication Research Reports, 22(3), 175-187.

Hendricks, A., \& Buchanan, S. (2013). From Exhaustion To Exhilaration: AssessingLibrarian Job Satisfaction With Virtual Reference. Library Hi Tech, 31(1), 42-63.

Khan, N., \& Zainab, T. (2015). Virtual Reference Services in modern libraries. International journey of digital library systems, 5(2), 1-17.

Kolthuri, M. K. (2014). An Overview of Virtual Reference Tools, Technologies and Services in Libraries. International Journal of Library and Information Studies, 4(4), 104-108.

Lancaster, S., Yen, D. C., Huang, A. H., \& Hung, S. Y. (2007). The selection of instant messaging or e-mail: College students' perspective for computer communication. Information Management \& Computer Security, 15(1), 5-22.

Lihitkar, S. (2011). Establishing a Virtual Reference Service. Journal of Library \& Information Technology, 31(1), 30-40.

Mu, X., Dimitroff, A., Jordan, J., \& Burclaff, N. (2011). A Survey and Empirical Study of Virtual Reference Service in Academic Libraries. The Journal of Academic Librarianship, 37(2), 120-129.

Nachbaur, A. (2003). College students and instant messaging: An analysis of chatting, flirting, and using away messages. Mercury Project for Instant Messaging Studies.

Nilsen, K. (2006). Comparing Users' PerspectivesOf In-Person And Virtual Reference. New Library World, 107(3/4), 91-104.

Pinto, M. \&. (2012). Virtual References Services: Defining The Criteria And Indicators To Evaluate Them. The electronic Library, 30(1), 51-69.

Radford, M. L., \& Connaway, L. S. (2007). creenagers" and live chat reference: Living up to the promise. Scan, 26(1), 31-39. 
Radford, M. L., Connaway, L. S., Pomerantz, J., Mon, L., \& Janes, J. (2008). E-valuating Ereference: Transforming digital reference through research and evaluation. Proceedings of the Association for Information Science and Technology, 45, pp. 1-11.

Rahaman, M. S., \& Ansari, K. (2011). Virtual Reference Services At The Main Library Of King Fahad University Of Petroleum And Minerals, Kingdom Of Saudi Aarabia: A Case Study. International Journal of Information Research, 1(1), 1-13.

Ruppel, M., \& Condit Fagan, J. (2002). Instant messaging reference: users' evaluation of library chat. Reference services review, 30(3), 183-197.

Shachaf, P., \& Horowitz, S. M. (20008). Virtual Reference Service Evaluation: Adherence to RUSA behavioral guidelines and IFLA digital reference guidelines. Library \& Information Science Research, 30, 122-137.

Vogus, B. (2020). Examining Virtual Reference Services in academic libraries. Public Service Quarterly, 16(4), 249-253.

Yang, S. Q., \& Dalal, S. A. (2015). Delivering Virtual Reference Services on the Web: An Investigation into the Current Practice by Academic Libraries. The Journal of Academic Librarianship, 41, 68-86. 


\section{Appendix}

\begin{tabular}{|c|c|c|}
\hline $\begin{array}{l}\text { What Virtual Reference Services were listed on the university library } \\
\text { site? }\end{array}$ & Live chat & E-mail \\
\hline $\begin{array}{l}\text { Approximately (to the nearest minute) how many minutes did you } \\
\text { browse the website before you were able to locate information indicating } \\
\text { whether the university library offered a virtual reference chat service? }\end{array}$ & & \\
\hline $\begin{array}{l}\text { How many links/webpages did you navigate to get from the homepage to } \\
\text { the general information page concerning Digital Reference Services? }\end{array}$ & & \\
\hline How many links/webpages did it take to get to the chat service? & & \\
\hline $\begin{array}{l}\text { Was there a search engine on the site to help find Digital Reference } \\
\text { Services? }\end{array}$ & Yes & No \\
\hline Was there a link/button inviting e-mail to ask questions about the site? & Yes & No \\
\hline $\begin{array}{l}\text { Did the link(s) to the digital reference service(s) include words on the } \\
\text { website that you did not understand? }\end{array}$ & $\begin{array}{l}\text { Yes } \\
\text { example-- } \\
-----\end{array}$ & No \\
\hline $\begin{array}{l}\text { Did the site use a divided window (or frame) to present the content of the } \\
\text { page? }\end{array}$ & Yes & No \\
\hline $\begin{array}{l}\text { Was the site was organized/presented in a way that made it easy to find } \\
\text { the link(s) leading to Digital Reference Services? }\end{array}$ & Yes & No \\
\hline $\begin{array}{l}\text { Did the site offered Help screens, FAQ help, or e-mail help, to assist with } \\
\text { the location of either the email reference service or the virtual chat } \\
\text { services? }\end{array}$ & Yes & No \\
\hline $\begin{array}{l}\text { Did the site use graphical buttons as links to the digital reference } \\
\text { services? }\end{array}$ & Yes & No \\
\hline If so, were the buttons clearly labeled or identified? & Yes & No \\
\hline Did you use a sitemap or site index to look for the chat? & Yes & No \\
\hline If so, was the sitemap useful to locate chat? & Yes & No \\
\hline
\end{tabular}

